\title{
Hierarchical Management of Hybridization of Energy Sources In EV's
}

\author{
Y. Mahadik ${ }^{1}$, K. Vadirajacharya ${ }^{2}$ \\ ${ }^{1}$ Research Scholar, DR. BATU,Lonere (MH),India. 2 HOD, Dept of EE, Dr. BATU Lonere-402103(MS)-India \\ \{yogi_maha@yahoo.co.in ${ }^{1} ;$ kvadirajacharya@dbatu.ac.in $\left.{ }^{2}\right\}$
}

\begin{abstract}
With strategic vision, to define objectives and to identify control strategy, requirements of energy and power should be known. To minimize peak power demand, Size, Cost and maximize efficiency, operating life of batteries hybridization of Battery and Ultra-Capacitor with power flow control is preferred.

In this paper Hierarchical Management is explained to decide control strategy of hybridization to control out Electrical parameters with long term (Specific Energy requirements) and Short term(Specific power requirements) are computed with respect to aerodynamic Electric vehicle model.
\end{abstract}

\section{Keywords: Lithium Ion, Ultra Capacitor, DC-DC converter, Energy management.}

\section{Introduction}

EV design is optimized when Energy storage system designed to meet all load demand without stress. Driving cycle demands instantaneous peak power with continuous energy but same source cannot cope up to meet High Specific power(HSP) and High specific energy (HSE) demand simultaneously ${ }^{[1]}$.

To fulfill all driving cycle demands, it is required to use HSP and HSE sources together with power flow control.

\subsection{Ragon Chart [5]}

Ragon plots gives an idea about energy capacity of various storage system. (specific power vs specific energy graph). From Ragon graph it is clear that to fulfill HSE demand storage batteries are used, whereas to fulfill HSP Demand ultracapacitors are used. High energy density offers High range of driving cycle, High power density provides instantaneous peak power requirements (High Acceleration). Hybridization of energy sources minimize size of Energy storage system (ESS), enhances life of storage batteries because of reduction in load current demand, Level of Depth of discharge (DOD)is maintained at optimum value.

In table-1 explained battery can be more suitable to provide HSE (which enhance driving range), whereas UltraCapacitor provides HSP (meet peak energy demands during acceleration, hill climbing). Hybridization (paralleloperation ) achieves benefits of both (HSP, HSE) demands.

Table.1. Comparison of energy storage elements [2] [3]

\begin{tabular}{cccccc}
\hline Sr. No. & Storage element & $\begin{array}{c}\text { Specific energy } \\
(\mathrm{wh} / \mathrm{kg})\end{array}$ & $\begin{array}{c}\text { Energy Density } \\
(\mathrm{wh} / \mathrm{Ltr})\end{array}$ & $\begin{array}{c}\text { Specific power } \\
(\mathrm{w} / \mathrm{kg}) 95 \% \text { eff }\end{array}$ & $\begin{array}{c}\text { Cycle } \\
/ \text { life }\end{array}$ \\
\hline 1 & Lead acid Battery & 40 & 80 & 100 & 1000 \\
2 & Ni-MH & 80 & 200 & $100-250$ & 2000 \\
3 & High energy Li-ion & 77 & 250 & $750-1500$ & 2000 \\
4 & Ultra Cap & 4.5 & 6.4 & 2000 & 500000 \\
\hline
\end{tabular}

B. Iyer, S. Nalbalwar and R. Pawade (Eds.)

ICCASP/ICMMD-2016. Advances in Intelligent Systems Research.

Vol. 137, Pp. 427-432.

(C) 2017- The authors. Published by Atlantis Press 


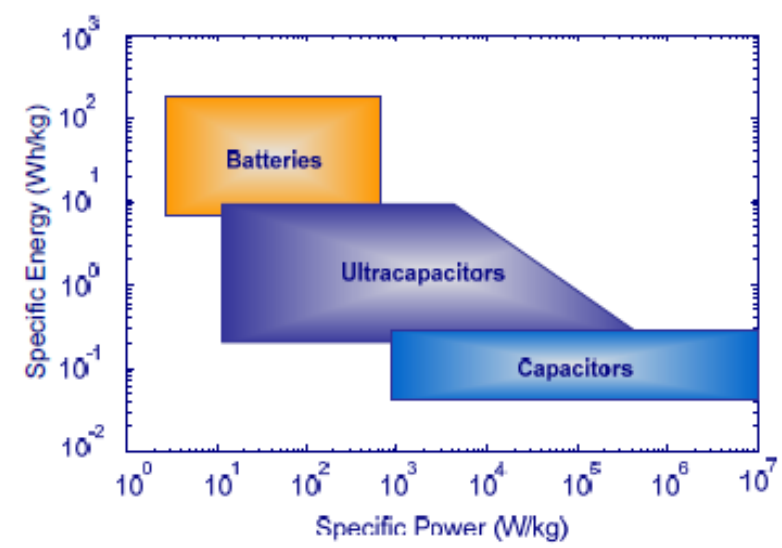

Fig.1. Ragon Chart [5]

\subsection{Energy Storage issues}

Electric vehicle having energy storage issues. Typically, EV stores energy in battery (usually lead-Acid, NiMH, Li-ion) those are very bulky, heavy expensive and less life. Due to these problems with current battery technologies, it is difficult to make EV general purpose. Charging time required is more.

\subsection{Energy requirements of driving cycle}

Following are the requirements from energy storage system (ESS) of EV.

1. Fulfill demand during high acceleration or high hill climbing capability.

Solution - High specific power (HSP) demand should be full filled by ESS within fraction of second e.g. ultracapacitor, flywheel, fuel cell etc.

2. Fulfill breaking requirement to obtain break power recovery

Solution - High specific power consumption by power recovery (by means quick charging capabilities) or called regeneration.

3. Fulfill high range driving cycle

Solution- Hybridization of HSE and HSP sources

4. To provide high range of driving cycle High specific energy (HSE) should be available with high rate.

Solution- Hybridization of HSE and HSP sources

5. Charging time should be reduced

Solution- Hybridization of HSE and HSP sources

\section{Multiple energy sources hybridization}

Sources normally uses either HSE or HSP capability but not both at-a-time. To fulfill HSE with HSP it is important to connect multiple energy sources (Hybridization of sources) with optimized management of energy flow HSE is favorable for long driving cycles, whereas HSP is used for high acceleration ${ }^{[1]}$.

\subsection{Advantages of hybridization of sources}

1. Great energy density and power density is obtained with reduced weight than independent use of ESS.

2. Life of battery depends on charging - discharging cycles, minimum Depth of discharging, that enhances using hybridization.

3. As ESS is designed for optimized power energy required, size and weight of system reduced.

4. Cost of energy storage system is reduced.

5. Efficiency of ESS enhances.

\section{ATLANTIS
PRESS}




\subsection{Operation with hybridization of ESS}

Table-2. Mode of operation

\begin{tabular}{cccc}
\hline & Load & Source & Opertation \\
\hline Accelaration & Motor & $\begin{array}{c}\text { Battry+ Ultra } \\
\text { Capacitor }\end{array}$ & Boost \\
Cruising & Motor & Battery & Boost \\
& $\begin{array}{c}\text { Ultracap } \\
\text { acitor+ } \\
\text { Breaking }\end{array}$ & Motor & Buck \\
& Battery & & \\
\hline
\end{tabular}

1. Acceleration

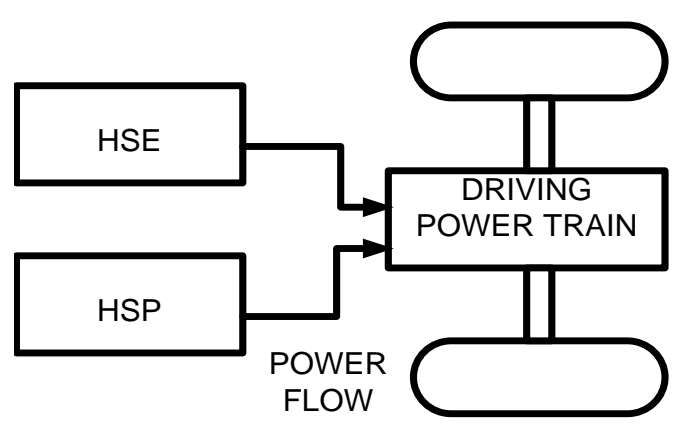

2. Cruising (Travel with constant speed)

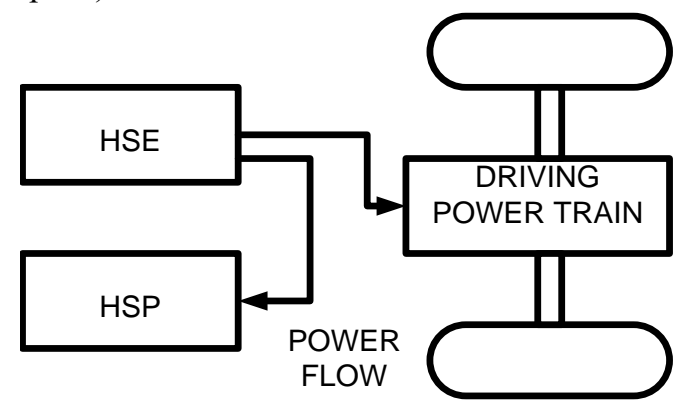

3. Breaking ( motor as generator)

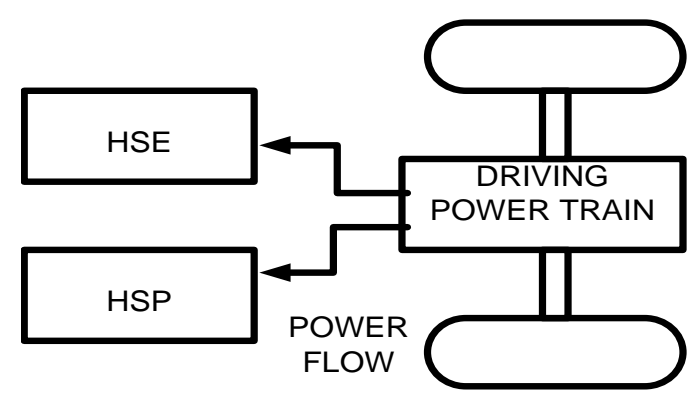

Fig.2. Operation with Hybridization 


\section{Hierarchical Energy management structure ${ }^{[1]}$}

For the optimized operation correct control decisions must be taken, which are classified as - Long term, Medium term, short term decisions synchronized with time. Energy management at upper level is more important than the power management hierarchically. This management strategy achieves optimized energy and power management system.

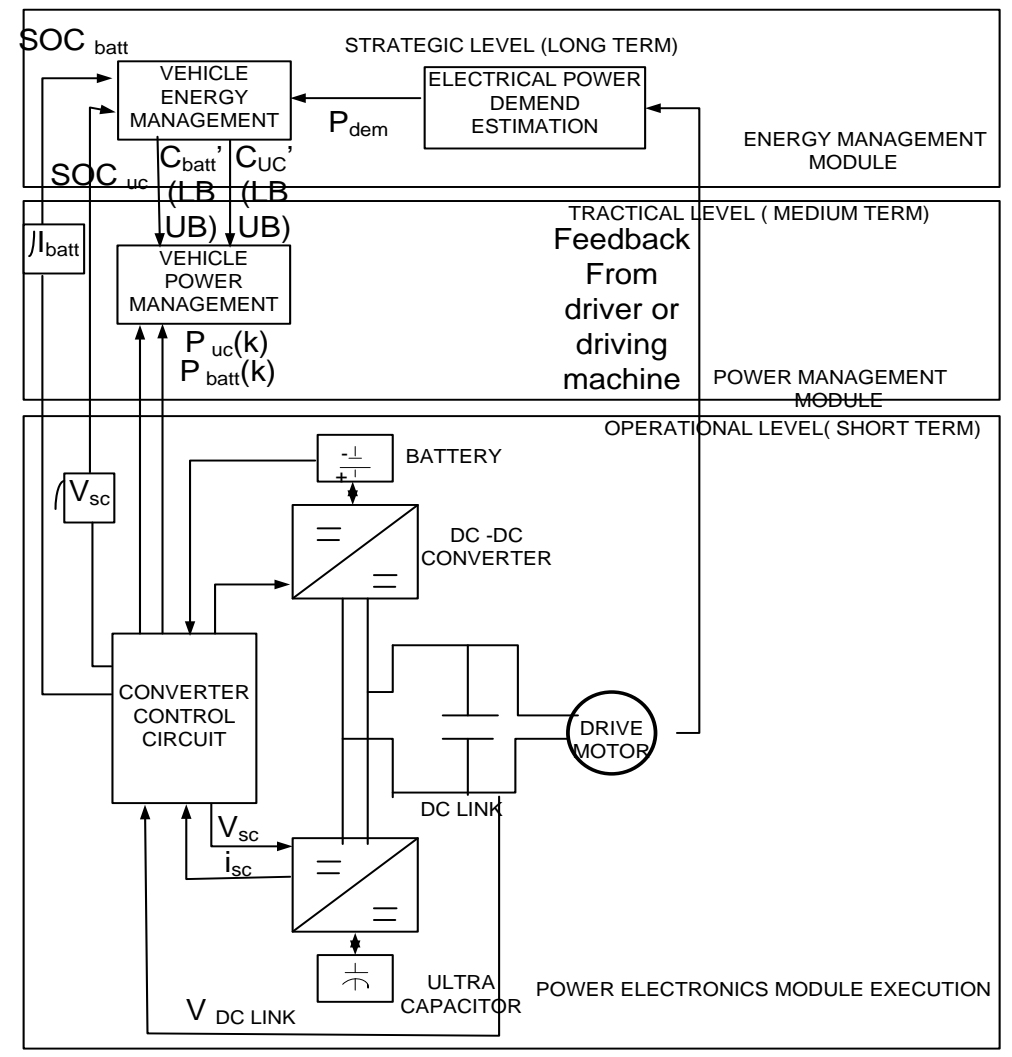

Fig.3. Hierarchical Energy management structure

With known driving cycle it is possible to differentiate power and energy requirements. In this approach energy requirements are determined by optimization using different constraints as driving range, speed and torque requirements, State of charge(SOC) of Energy storage system(ESS) elements. Reference signal for hybridization based upon optimization to fulfill energy requirements whereas power requirements on the basis of driver acceleration characteristics and torque requirements.

Operational flow chart is designed as follows.

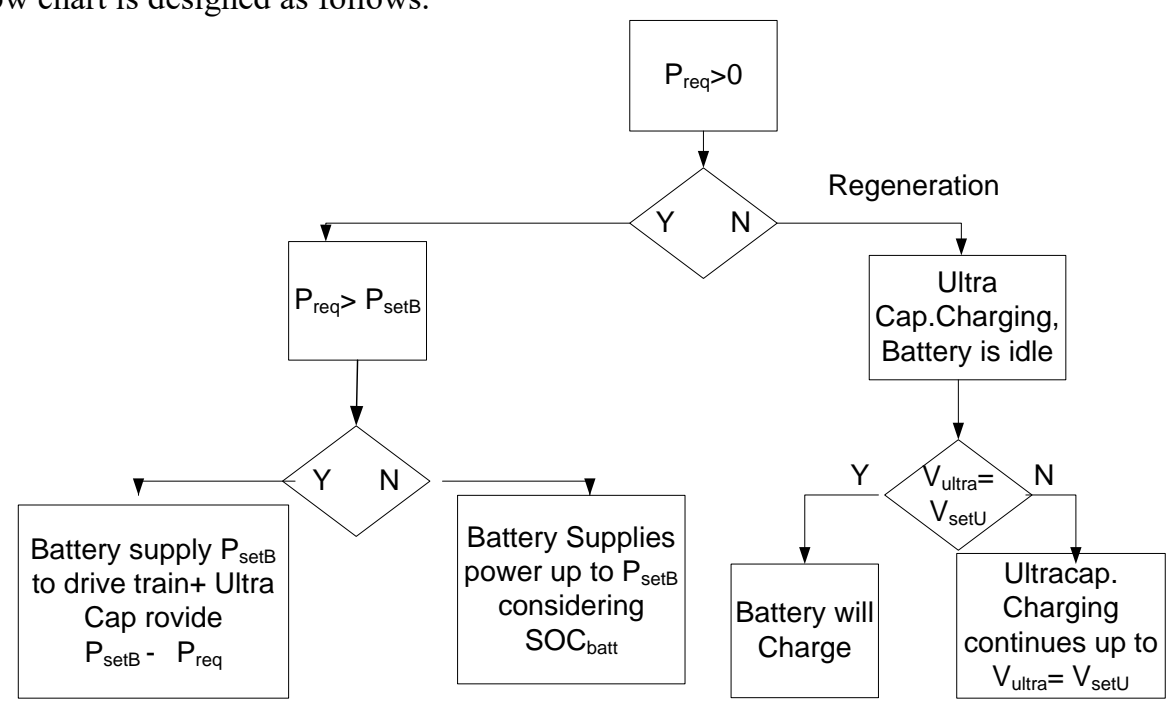

Fig.4. Operational Flow Chart ${ }^{[4]}$ 
Torque requirements are taken from motor (drive train) references and control system is designed with Fuzzy (Long term decisions) and Classical Pi (for short term decisions). In proposed work penetration of sources are designed based upon SOC (or DOD) and Hierarchical Energy Management is implemented.

\section{EV Dynamic model}

Transfer function requires load and mass consideration of vehicle with dynamic and aerodynamic characteristics EV model is implemented ${ }^{[1]}$.

Let-

$\mathrm{m}=$ mass of Vehicle

Opposite forces-

$\mathrm{F}_{\mathrm{rr}}=$ Frictional force

$\mathrm{F}_{\mathrm{ad}}=$ Aerodynamic drag

$\mathrm{F}_{\mathrm{nc}}{ }^{\prime}=$ Climbing force

$\mathrm{F}_{\mathrm{ad}}=$ aerodynamic theory ignoring the lateral forces

( square of vehicle velocity)

Total tractive Effort ( Sum of rolling resistance force)

$\mathrm{F}_{\mathrm{r}}=\mathrm{F}_{\mathrm{rr}}+\mathrm{F}_{\mathrm{ad}}+\mathrm{F}_{\mathrm{hc}}$

$F_{r}$ depends on the coefficient of rolling resistance $\left(\mu_{\mathrm{rr}}\right)$.

$\mu_{\text {rr }}$ considered 0.015 (for conventional tires) and 0.005

( for special EV tires).

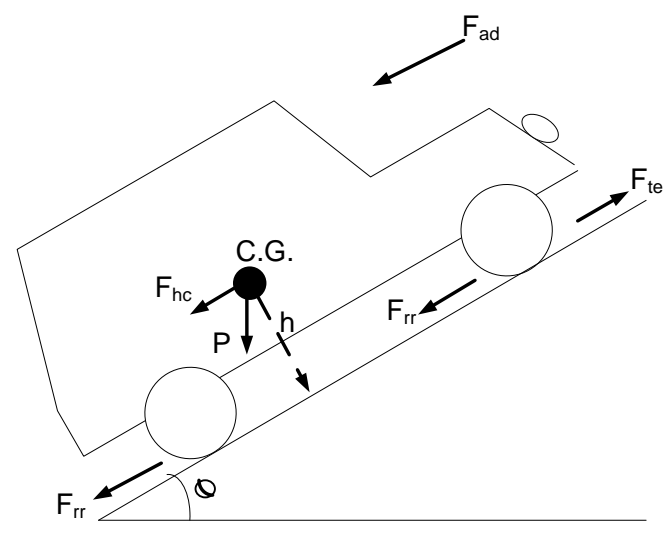

$\rho$ is air density

Fig.5. EV Model

$\mathrm{C}_{\mathrm{p}}=$ drag coefficient

$\mathrm{A}_{\mathrm{F}}=$ Front projection area

$\mathrm{V}_{\mathrm{v}}=$ vehicle speed relative to wind.

Thus the power applied to the motor, necessary to overcome $\mathrm{F}_{\mathrm{r}}$ increases with the cube of speed.

Consider the ideal mechanical transmission,

$$
F_{r}=\mu_{r r} m g+\frac{1}{2} \rho C_{D} A_{F} V_{v}^{2}+m g \sin \theta
$$

Torque results from set vehicle resistance forces $\left(F_{R}\right)$

$$
T_{m}-\frac{r}{i} F_{R}=J_{T} \frac{d \mathfrak{w}_{m}}{d t}
$$

Where,

$\mathrm{r}=$ wheel radius

$\mathrm{i}=$ gear transmission ratio

$\mathbf{w}_{\mathrm{m}}=$ motor angular speed

$\mathrm{T}_{\mathrm{m}}=$ motor drive

$\mathrm{J}_{\mathrm{T}}=$ moment of inertia

$\varepsilon=$ Slipping of wheels

Where,

$\mathrm{J}_{\mathrm{m}}=$ inertia from electric motor

$$
J_{T}=J_{m}+J_{r}+\frac{1}{2} m\left(\frac{r}{i}\right)^{2}(1-\varepsilon)
$$


$\mathrm{J}_{\mathrm{r}}=$ inertia from wheels

Mechanical power needed on the wheels $\left(\mathrm{P}_{\mathrm{u}}\right)$

$$
P_{u}=T_{m} \cdot \omega_{m}
$$

Required electric power $\left(\mathrm{P}_{\mathrm{e}}\right)$

$$
P_{e}=n_{t o t} \cdot P_{u}
$$

EV model gives electric power requirement as per mechanical design. Power requirements can be calculated using EV model for rural or urban cycle. On the basis of power and energy requirement modeling with metaheuristic approach can be obtained.

\section{Conclusion}

EV model gives electrical power requirement considering aerodynamic constraints of EV. For long term decisions rule based approach (fuzzy-Neural) can be used and short term decision Classical PI is implemented. Best solution on the basis of Hierarchical management can be identified by heuristic approach of optimization (by narrowing search space) to generate converter control signals within minimum computation time, e.g. FuzzyNeural Network ${ }^{[1][6]}$ or by computing transfer function of the system and model designed on the basis of torque speed requirement and state of charge and driving range.

\section{References}

[1] Paulo G. Pereirinha, "Multiple energy sources Hybridization : The future of electricvehicles?",INTECH book, pp 237-264.

[2] Lei Wang, "Optimal design and Real time control for energy management in Electric Vehicles" vol 60 no 4 pp 1419-1429 may 2011.

[3] A.F. Burke, "Batteries and ultracapacitor for electric, hybrid and fuel cell vehicles" Proc.IEEEvol 95 no.4, pp 806 to 820,2007

[4] Rebecca Carter "Optimizing for Efficiency or Battery Life in a Battery/Supercapacitor Electric Vehicle", Ieee Transactions On Vehicular Technology, Vol. 61, No. 4, May 2012

[5] F. S. Gracia, "Control strategy for Battery- Ultra capacitor Hybrid Energy storage system ", Proc. IEEE vol :978-1, pp-826-832.

[6] Felipe Machado, "Effectiveness of Supercapacitors in Pure Electric Vehicle Using a Hybrid MetaHeuristic Approach" IEEE Transactions On Vehicular Technology, 2015 